\title{
ANÁLISE CONCEITUAL E HISTÓRICA DOS PARQUES URBANOS: IDENTIFICAÇÃO DE CENÁRIOS APTOS EM RONDONÓPOLIS-MT
}

Werlen Gonçalves Raasch ${ }^{1}$

Antonia Marilia Medeiros Nardes²

\section{INTRODUÇÃO}

O espaço geográfico urbano ou rural está sujeito as relações sociais e as da natureza. Atuando de forma sistemática ou não, são as ações derivadas desse sistema, que operam na produção do espaço geográfico.

Considerando a sinopse histórica dos problemas socioambientais que emergiram, sobretudo pós-revolução industrial, no ápice do sistema, a luta de ambientalistas, Instituições e os vários setores da sociedade civil organizada, garantiram via jurisprudência, ferramentas de proteção a biodiversidade global, bem como a sensibilização por ações mais sadias entre o homem e a natureza, almejando qualidade ambiental e bem-estar social.

Na retórica urbana capitalista, contrapondo esse cenário, as Áreas Verdes tornaram-se uma importante ferramenta na busca por melhoria da qualidade ambiental e de vida da população (REZENDE et al, 2012).

Compreendendo os Parques Urbanos como um tipo de Área Verde, essas áreas tornaram-se um recinto da vida florística e faunística nas cidades, sendo também um espaço propício para retomada da naturalidade humana, desempenhando relações mais coletivas e menos individuais, mais sustentáveis e menos artificiais. Nesse sentido, ao compreender a evolução dos Parque nos processos histórico, social, ambiental e urbano e a identificação dos cenários aptos à implantação de Parques em Rondonópolis a

1 Graduando em Licenciatura Plena em Geografia/CUR/UFMT. Membro do Grupo de Pesquisa Planejamento, Ambiente e Educação Ambiental - PLANEA. Bolsista PIBIC.

2 Prof. Dra. Associada do Depto de Geografia CUR/UFMT. Líder do Grupo de PesquisaPLANEA. 
proposta científica é de grande importância para as comunidades científica e em geral.

Trazendo essa temática para a área de estudo, a cidade de Rondonópolis não dispõe de nenhuma Área Verde com perfil de Parque Urbano apto ao uso, por sua vez, oito Parques já foram criados na cidade a partir de 2005, mas não foram implantados. Na busca por respostas, a especulação imobiliária é um dos fatores a ser considerado. E a ausência de políticas públicas efetivas que visam a implementação de áreas com esse perfil também corrobora com este cenário atual.

No entanto, na mancha urbana de Rondonópolis existem áreas que possuem fragmentos de vegetação e cursos d'água, contendo atributos ambientais relevantes para efetivar o lazer, o bem-estar social e desenvolver a estética paisagística urbana, configurando-se como cenários aptos a implantação de Parques Urbanos, mesmo que com menores proporções territoriais.

O Parque Urbano é um espaço necessário para a efetivação da unidade urbana com as amenidades ambientais, correlacionando a $(\mathrm{Re})$ produção social e os elementos bióticos e abióticos em um ambiente equilibrado.

\section{Parques Urbanos: Análise Conceitual}

As obras literárias acerca do conceito de Parque Urbano, consideram o Parque como um tipo de Área Verde, que foram englobadas pela definição maior de Espaços Livres.

Nos estudos de Ferreira (2005), Loboda \& Angelis (2005), Benini \& Martin (2014) e Bargos \& Matias (2011), todos fazem referência a definição presente no Artigo de Lima et al. (1994), intitulado de "Problemas de Utilização na Conceituação de Termos como Espaços Livres, Áreas Verdes e Correlatos", publicado em 1994 nos Anais do II Congresso Brasileiro de Arborização Urbana, em São Luís/MA.

$\mathrm{O}$ artigo conclui que Espaço Livre é mais abrangente e este integra os demais conceitos que visam definir os espaços construídos em áreas urbanas que se tenha a presença do verde e visa, sobretudo o lazer, o estético e a qualidade ambiental. Contudo "tal conceito tem que ser integrado ao uso do espaço, sua escala 
e função, devendo, esta última, satisfazer três objetivos principais: ecológicos, estético e de lazer (LIMA et al., 1994)". Com base nos conceitos de Lima et al (1994), elaboramos um organograma (Figura 1), para melhor contextualizar essa definição.

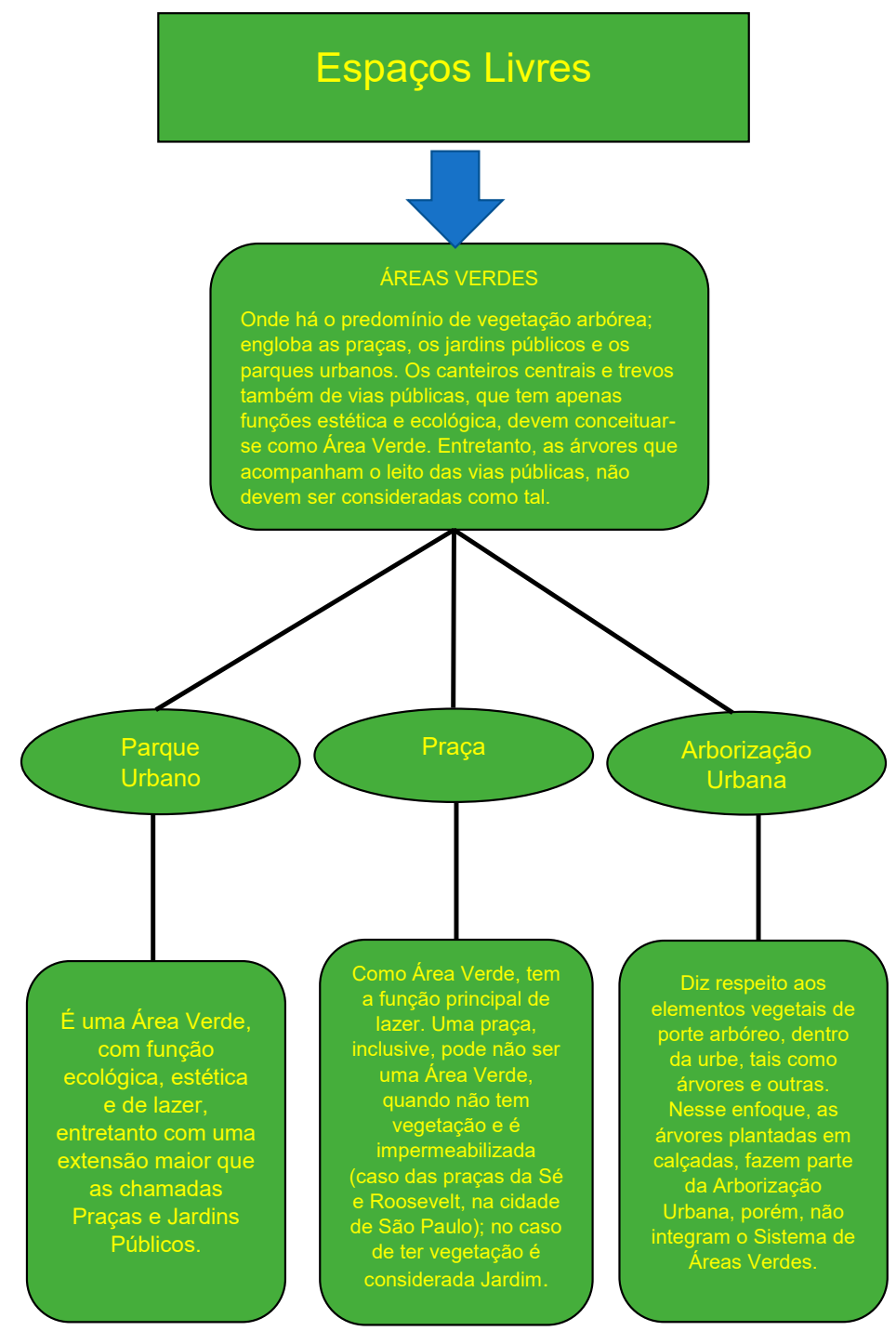

Figura 1: Organograma adaptado do conceito de LIMA et al. (1994)

Fonte: RAASCH (2017) 
Nessa perspectiva, a Resolução N³69/2009 da CONAMA, Art. $8, \S 1^{\circ}$, considera Área Verde urbana "[...] o espaço de domínio público que desempenhe função ecológica, paisagística e recreativa, propiciando a melhoria da qualidade estética, funcional e ambiental da cidade, sendo dotado de vegetação e espaços livres de impermeabilização". Em suma, áreas que possuem cobertura vegetal arbórea, arbustiva e/ou gramíneas, que venha contribuir para a qualidade de vida e o equilíbrio ambiental da cidade. A vegetação pode estar situada nos canteiros centrais, nas Praças, Parques, florestas, terrenos públicos e privados não edificados, Unidades de Conservação e Áreas de Proteção Permanente (APP), conforme o Ministério do Meio Ambiente (2009).

Considerando a abrangência de Área Verde, e o desenvolvimento histórico-temporal do conceito de Parque Urbano, Ferreira (2005) afirma que o Parque assume papel importante nas cidades contemporâneas, desempenhando funções socioambientais, ecológicas e de lazer.

\section{A Narrativa dos Parques Urbanos}

O século XV e XVI são marcados pela manifestação do Renascimento, movimento que influenciou os paradigmas culturais, sociais e econômicos, e também no âmbito das investigações científicas de valorização da natureza. Os renascentistas mudaram consideravelmente a mentalidade ocidental, de modo que a sociedade urbana abandonará aquele imaginário da natureza selvagem, vendo a natureza como solução para os problemas socioambientais que estavam surgindo nas cidades europeias (FERREIRA, 2005). Nesse período, "os jardins botânicos começam a ser planejados com a mesma preocupação estética utilizada nos jardins de prazer, ou seja, jardins que proporcionam momentos de plena satisfação (TERRA 2004, apud FERREIRA, 2005, p. 21)." A priori essas áreas eram sobretudo privadas, e em suas formas prevaleciam o homem dominando a natureza (ANDRADE, 2004).

Considerando a evolução dos jardins no continente europeu:

O jardim inglês com seus elementos sinuosos, seu romantismo, sua nova estrutura, seus componentes engraçados e loucos criam, com árvores plantadas pelo homem, um 
ambiente com o aspecto natural. A natureza deve parecer intocada e não um trabalho realizado pelo homem. Esse modelo de jardim mais usado na França, chega depois ao Brasil. É um novo pensar sobre a natureza (TERRA 2004 apud FERREIRA, 2005, p. 22).

No século XVIII e XIX foram criados os primeiros espaços ajardinados públicos. As mudanças estruturais provocadas pela Revolução Industrial, sobretudo na infraestrutura das cidades, promoveram a criação dos primeiros Parques Urbanos nas cidades Inglesas.

A retirada de vegetação combinado a expansão urbana, foi contraposta pelas ideias higienistas do século XIX, estes passam a defender a criação dos Parques com intuito de elevar a qualidade de vida da população, transformando-os em pulmões das cidades, melhorando a qualidade do ar poluído pelas indústrias (SANTUCCI, 2003).

Portanto, os Parques europeus emergiram por conta do novo cenário posto pela industrialização, expansão da mancha urbana, boom demográfico e problemas no âmbito social e ambiental, visando atender as necessidades das massas urbanas (MACEDO; SAKATA, 2002).

No contexto brasileiro, a realidade era outra, até o século XIX o país não tinha cidades com mancha urbana expressiva, as cidades do Rio de Janeiro, São Paulo, Salvador, Porto Alegre não eram industrializadas, faziam apenas intercâmbio dos produtos que entravam no Brasil e saiam para a Europa (MACEDO; SAKATA, 2002).

Mas nesse período era comum as famílias da época possuírem casa nas cidades, próximo aos negócios, e outra no campo, utilizando as fazendas também como uma ferramenta de lazer. Neste momento, Petrópolis e Teresópolis no então Estado do Rio de Janeiro, tornaram-se destino das elites cariocas, por possuírem Parques e palacetes (MACEDO, 1999).

Portanto, os Parques Urbanos no Brasil surgem inicialmente para atender a elite, com o propósito de configurar as cidades brasileiras nos moldes europeu. Mas esse cenário se altera com a chegada da família Real portuguesa ao Rio de Janeiro em 1808, que logo solicita a construção do Jardim Botânico.

Nesse contexto são criados, no Rio de Janeiro, os três primeiros parques públicos, com as características morfológicas e funcionais que conhecemos hoje: o campo de Santana e o Passeio Público, situados junto ao núcleo histórico e centro 
tradicional da cidade, e Jardim Botânico, junto a então distante Lagoa Rodrigo de Freitas (MACEDO; SAKATA, 2002).

O século XIX é um momento de estruturação do Brasil, e reestruturação das cidades, pois estas ganham novas funções, sendo um momento de modernização. E a cidade do Rio de Janeiro como a nova capital, precisava-se equiparar ao nível eurocêntrico.

Por todo século XIX e até a segunda metade do século XX, as cidades brasileiras possuíam grandes vazios urbanos, e as características naturais com rios, riachos, praias e várzeas, somados a tropicalidade, proporcionavam muitas possibilidades de lazer, de modo que o Parque Urbano neste momento era pouco significativo.

Nessa perspectiva, Macedo (1999) contextualiza a popularização do banho de mar na primeira metade do século $X X$, que potencializou o surgimento do bairro de Copacabana na cidade do Rio de Janeiro, e avenidas praieiras em Santos e Guarujá no Estado de São Paulo. E ainda, nos anos 50 as casas de veraneio provocaram um boom imobiliário, consolidando-se essa prática em todo o Brasil nas próximas décadas.

Macedo (1999) contextualiza o movimento de todas as camadas sociais para o exercício do lazer na segunda metade do século $X X$, tendo em vista que os moradores do interior têm como rota as praias, já os residentes do litoral dirigem-se as montanhas e/ou o campo, sobretudo no período de férias ou feriado.

A busca pelo lazer entrou definitivamente em pauta na sociedade, tornando-se um bom negócio para o mercado, além de gerar qualidade de vida para as pessoas. Assim, surgem clubes urbanos na sua maioria privados, academias de ginástica, shoppings, parque de diversões, se fomenta o teatro e os festivais culturais, abrindo-se um leque de opções sobretudo para a classe média (MACEDO, 1999).

Mas ainda permanecia a necessidade de criação de espaços públicos para a prática de lazer das grandes massas, e que também aproximava os moradores urbanos de ambientes naturais, promovendo entre outras coisas saúde pública.

Desta forma, considerando a evolução dos Parques Urbanos, este se tornou uma ferramenta que iria ao encontro dessa demanda socioambiental, passando a ser inserido no cenário urbano brasileiro, a princípio nas cidades mais importantes do país. 
Os primeiros grandes Parques implantados no território nacional com a proposta de lazer público para as massas surgiram de forma isolada na década de 50, como o Parque do Ibirapuera em São Paulo/SP e o Parque do Flamengo no Rio de Janeiro/RJ, onde esses dois foram estruturados para recreação, contendo equipamentos esportivos (SANTUCCI, 2003).

Por sua vez, as cidades pequenas e os centros/polos regionais, tradicionalmente não possuem uma política forte de implementação de Parques Urbanos ou espaços de lazer com área e/ou estrutura relevante, sobretudo em determinadas regiões do país.

Nesse caso, a ausência de planejamento urbano e a falta de mentalidade para idealizar cidades modernas que visam atender ás necessidades da população urbana são fatores a serem questionados. E ainda, os gestores públicos podem não considerar que cidades na faixa entre 50 mil a 200 mil habitantes, também apresentam graves problemas socioambientais acentuados, considerando ainda que as cidades com menos de 50 mil habitantes estejam conectadas com um ambiente bucólico, sendo esta última uma conclusão equivocada, pois os Parques contribuem para a saúde pública.

Nessa perspectiva, a cidade de Rondonópolis sendo um polo econômico regional no Sul do Estado de Mato Grosso, com 53 anos de emancipação política administrativa, com população estimada em 2016 de 218.899 mil habitantes, segundo o Instituto Brasileiro de Geografia e Estática (IBGE), entra no grupo de cidades que possuem carência de espaços com a funcionalidade de Parques Urbanos.

Considerando essa problemática, iremos identificar áreas com potenciais a criação e posteriormente efetivação de Parques Urbanos.

\section{PROCEDIMENTOS METODOLÓGICOS}

O referencial teórico desse estudo está calcado em livros, monografias, dissertações, teses e artigos. Com o desenvolvimento do arcabouço teórico viabilizou compreender a evolução dos Parque nos processos históricos, sociais, ambientais e urbanos.

A pesquisa documental, acerca das políticas públicas que envolvem a criação e a implementação de Parques Urbanos na área 
de estudo, se sucedeu com base no Sistema Nacional de Unidades de Conservação (SNUC) e o Plano Diretor do Munícipio de Rondonópolis de 2006.

A identificação das áreas que compreendem os cenários aptos a implantação de Parques na mancha urbana, foram realizadas por meio do programa Google Earth e do Trabalho de Campo.

Por meio do Trabalho de Campo realizamos a identificação dos cenários aptos, observando as características das áreas e entorno. Os campos realizados especificamente para essa pesquisa em Rondonópolis, aconteceram nos dias 26/06/2017 e 07/07/2017.

O mapa dos cenários foi elaborado a partir de dados do IBGE e espacializados por meio dos Softwares Google Earth e ArcGis 10.1.

\section{A Concentração da Terra e os Cenários Aptos a Implantação de Parques Urbanos em Rondonópolis}

Os centros urbanos passam por processos que valorizam demasiadamente a terra, motivado sobretudo pela especulação imobiliária, sustentada na apropriação do território pela iniciativa privada. Esse processo deriva grandes vazios demográficos, expandindo a mancha urbana e distanciando os serviços de infraestrutura técnica e social das classes menos favorecidas, empurrando-os para as áreas periféricas.

Nessa perspectiva, a valorização da terra também incita a ocupação das APPs dos córregos e rios que cortam a cidade pela classe mais pobre da população, que busca sua morada. Esse desrespeito aos limites mínimo de preservação provoca graves problemas socioambientais como desmatamento, erosão, assoreamento, enchentes e deslizamentos que afetam as moradias, além do despejo de resíduos sólidos e dejetos nos corpos d'água.

Negri (2008) expõe que o mercado imobiliário de Rondonópolis é o responsável pela separação das classes sociais no espaço, e que quase sempre os mais pobres são obrigados a ocupar terrenos públicos ou privados sem infraestrutura localizados nas zonas periféricas, processo resultante da segregação socioespacial.

A concentração da terra pela iniciativa privada é um fator que dificulta a criação de Parques Urbanos em Rondonópolis, pois provoca a escassez de terras públicas. E os vazios deixados na 
mancha urbana, utilizados como reserva de valor, acabam por ser inóspitos de elementos naturais relevantes, sendo áreas pouco propícias à instalação de Parques.

Diante do contexto, foram identificados oito cenários aptos a implantação de Parques Urbanos na mancha urbana de Rondonópolis (Figura 2). Esses contemplam APPs de córregos da cidade e do Rio Vermelho, abrangendo as ZUC, conforme estabelecido no Plano Diretor, aumentando a importância da criação de mais uma ferramenta de proteção ambiental, pois como explanado, as APPs por si só não estão garantindo a invasão de edificações nas zonas de drenagem.

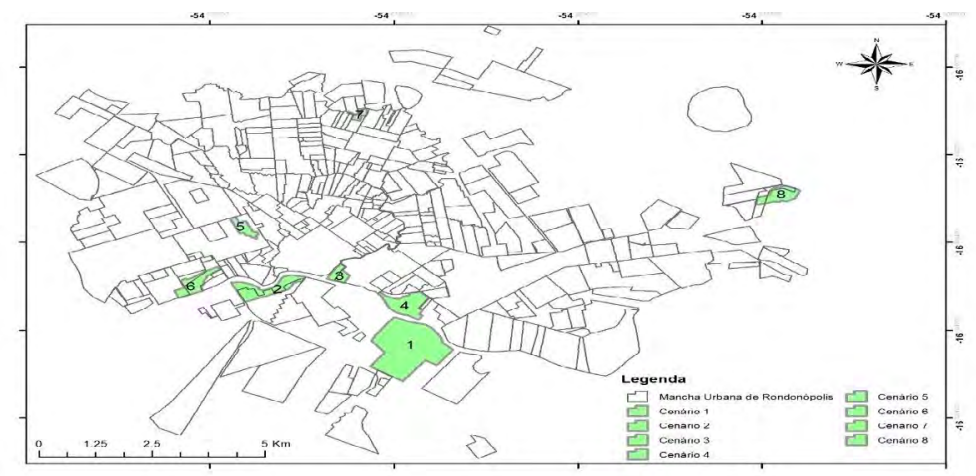

Figura 2. Cenários aptos a criação de Parques na mancha urbana de Rondonópolis Fonte: Nogueira; Raasch (2017)

O Cenário 1 está situado ao leste do Parque da Seriema, e contém cerca de 216,17 hectares, contemplando parte da planície de inundação do córrego Lourencinho e APP da margem esquerda do Rio Vermelho. O Plano Diretor de 2006 já havia recomendado a criação de uma Unidade de Conservação no interior de um Parque Urbano neste local, mas até o momento não existe projeto para essa área. A respectiva área apresenta uma rica biodiversidade influenciada por uma categorização de vegetação como arbóreas, arbustivas e herbáceas, principalmente espécies pertencentes ao bioma cerrado, pois sendo um abrigo para uma variada fauna (Figura 3). 


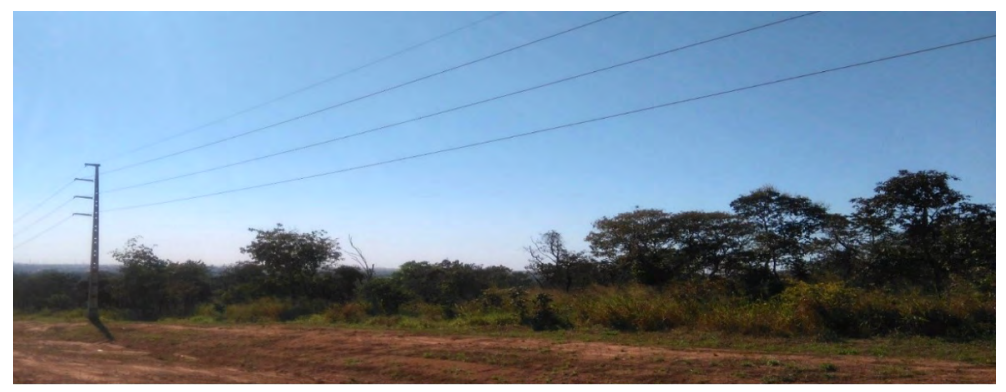

Figura 3. Fragmento vegetacional na margem da Av. Otaviano Muniz, no Cenário Fonte: Raasch (2017).

O Cenário 2 está localizado no sentido oeste do Parque da Seriema, contendo 52,32 hectares, que a priori faria parte dos limites geográficos do respectivo Parque lançado em 2014, sendo identificada como área propícia pelo Poder Público.

O cenário contempla uma superfície coberta por mata, a foz do córrego Lourencinho e uma área propícia a inundação do Rio Vermelho no período de cheias. Nas proximidades da BR-364 forma-se substancialmente uma pequena lagoa intermitente, originado por períodos de alto índice pluviométrico e/ou a cheia do Rio Vermelho (Figura 4).

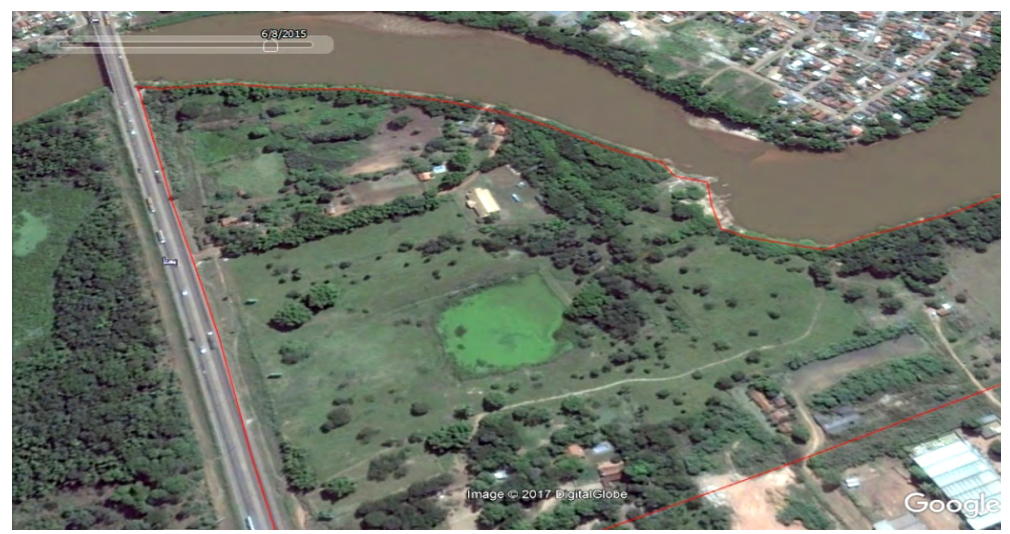

Figura 4. Lagoa próximo a margem direita do Rio Vermelho no Cenário 2 Fonte: Imagem de satélite disponível no Google Earth (08/06/2015)

As propriedades particulares em frente a rodovia possuem pastagem em quase todo o terreno, contendo apenas resquícios de mata nativa (Figura 5). 


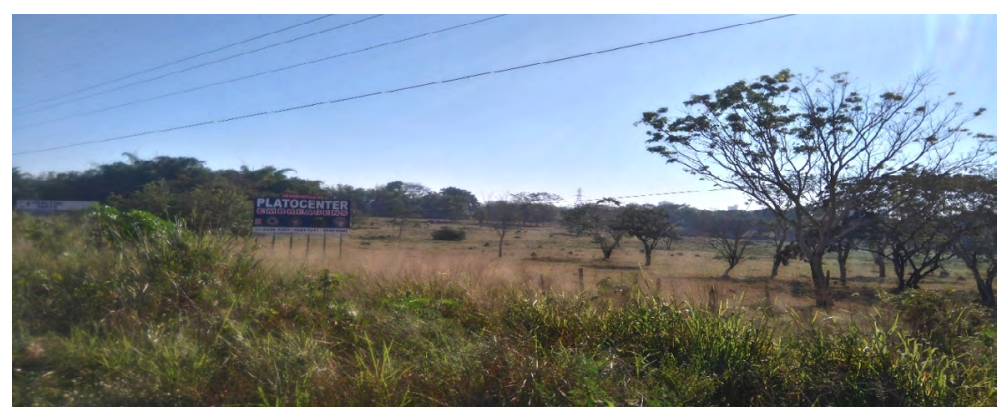

Figura 5. Espécies vegetais em área de pastagem no Cenário 2

Fonte: Raasch (2017).

A criação de Parques no sentido leste e oeste do Parque Seriema criariam uma zona de amortecimento, aumentando a proteção sobretudo do Rio Vermelho, e evitando que essas áreas com grande diversidade biológica no entorno do rio, sejam assediadas pelo mercado imobiliário.

No Cenário 3, localizado no encontro do córrego Arareau com o Rio Vermelho, na região central de Rondonópolis, houve uma tentativa de implantação do Parque das Águas. O ideal seria a retomada do projeto, pois a área possui cerca de 16 hectares, de modo que o Parque atuaria na conservação da APP do Rio Vermelho daquela região, que está sendo assediada pelo mercado imobiliário, onde grandes empresas como o Supermercado Big Master e as Lojas Havan construíram suas filiais na APP e zona de amortecimento, beneficiando-se da logística do local, e do tráfego intenso de carros que passam na avenida Fernando Corrêa da Costa.

Ainda que a área tenha empecilho por conta de uma propriedade privada, que inclusive desrespeita o limite da APP do córrego Arareau, desmatando-a para plantar pastagem e criar gado (Figura 6), o Poder Público poderá resolver essa questão se embasando no direito de preempção, pois a área é relevante ambientalmente e poderá também ser socialmente com a implantação de um Parque Urbano no único cenário apto existente no centro da cidade. 


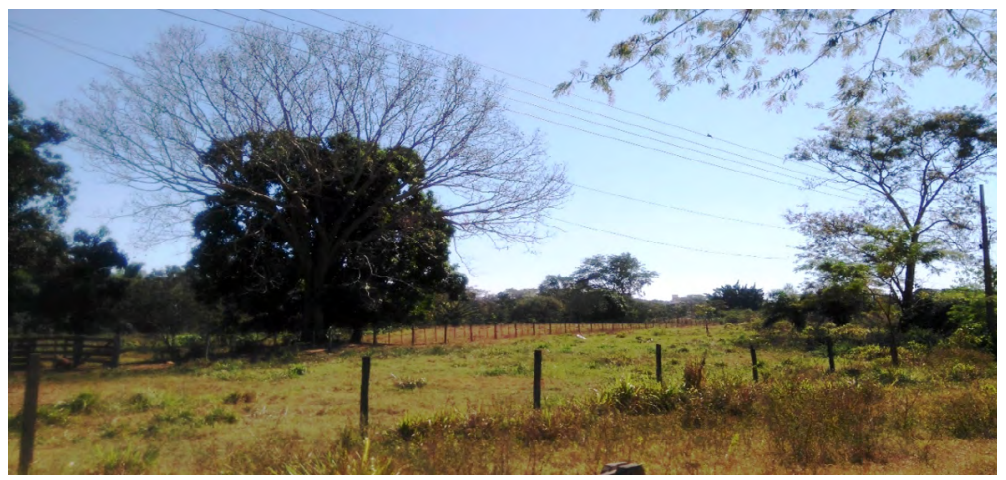

Figura 6. Cenário 3 com área de pastagem no entorno da APP do córrego Arareau Fonte: Raasch (2017).

O Cenário 4 é uma área de aproximadamente 51,44 hectares, que contemplam chácaras e um grande trecho da APP da margem direita do Rio Vermelho. A área possui superfície irregular, contendo indícios de recalque de solo, tornando-se uma área com alta suscetibilidade para a urbanização.

Desta forma, é recomendável a criação de um Parque Urbano para restaurar o que já foi desmatado e manter a vegetação existente, podendo ser criado trilhas ecológicas, desenvolver práticas de Educação Ambiental e construir até um mirante para contemplação da margem do Rio Vermelho (Figura 7).

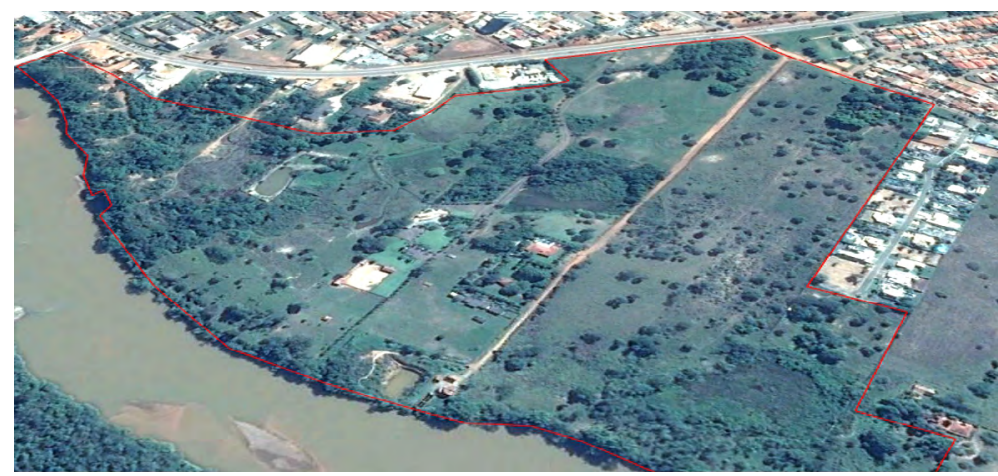

Figura 7. Cenário 4 com resquícios de vegetação e APP desmatada na margem direita do Rio Vermelho

Fonte: Imagem de satélite disponível no Google Earth (06/02/2017). 
O Plano Diretor de 2006 recomendou a criação de um Parque Municipal, no Cenário 5 denominado André Maggi. Aárea de aproximadamente 16,52 hectares, situa-se nos fundos da Faculdade Anhanguera, na Vila Birigui. Em 2013 a gestão municipal cogitou em criar no local o Parque das Emas, mas nunca se foi elaborado nem um projeto, inexistindo ações concretas que pudessem criar o Parque.

Uma parte da área é pública e a outra é propriedade privada, fator que dificulta o processo de implantação de um Parque Urbano, pois as residências do entorno são de alto padrão, valorizando as terras dessa região da cidade. Nesse sentido, o secretário atual do meio ambiente informou que o proprietário pediu uma quantia altíssima para vender a área para o município, mas que a Prefeitura utilizou o direito de preempção, para ter preferência na aquisição do terreno.

A área situa-se em um vale, sendo propício para nascentes, de modo que existiu um córrego perene nascendo mais acima, nas proximidades do Caiçara Tênis Clube. $\mathrm{O}$ desmatamento em provimento da urbanização culminou no desaparecimento da lâmina d'água, mas que deve reaparecer no período das chuvas no fragmento vegetacional dentro do respectivo Cenário (Figura 8).

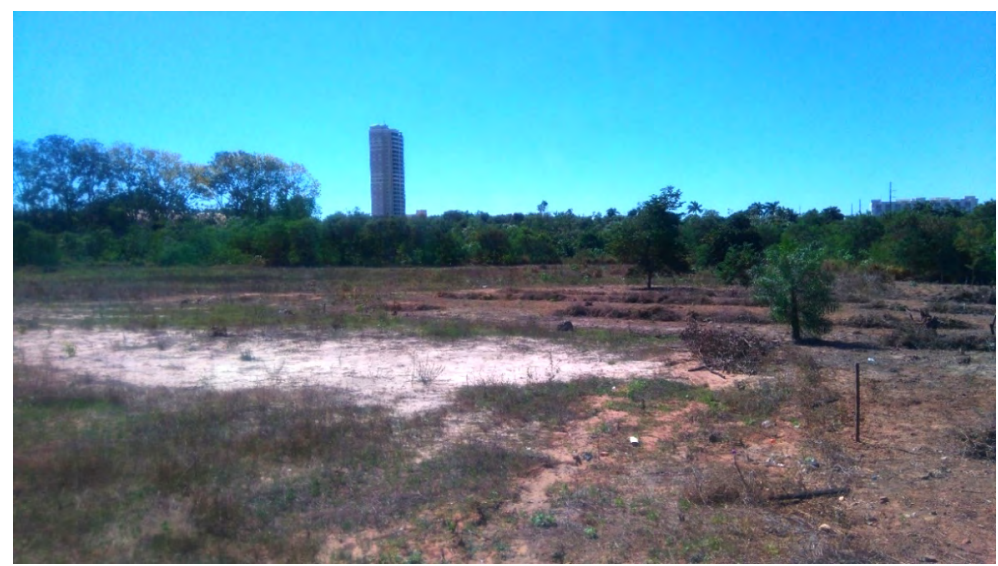

Figura 8. Fragmento Vegetacional no Cenário 5, localizado na Vila Birigui Fonte: Raasch (2017) 
O Cenário 6 é uma área de 34 hectares, localizada entre a Vila Mamed e o Jardim Maracanã, que vai desde a margem da BR-364 até a Estação de Tratamento de Água (ETA). O local compreende a foz de um córrego que nasce nas proximidades da avenida José Pinto no Jardim Paineiras e deságua no Rio Vermelho.

No entorno foram criados recentemente um grande conjunto habitacional de casas populares, de modo que um Parque Urbano naquela região será um ponto de referência para a prática de lazer dos moradores, e também atuará na proteção do córrego e da APP do Rio Vermelho, que foi invadida com a construção da Vila Mamed (Figura 9).

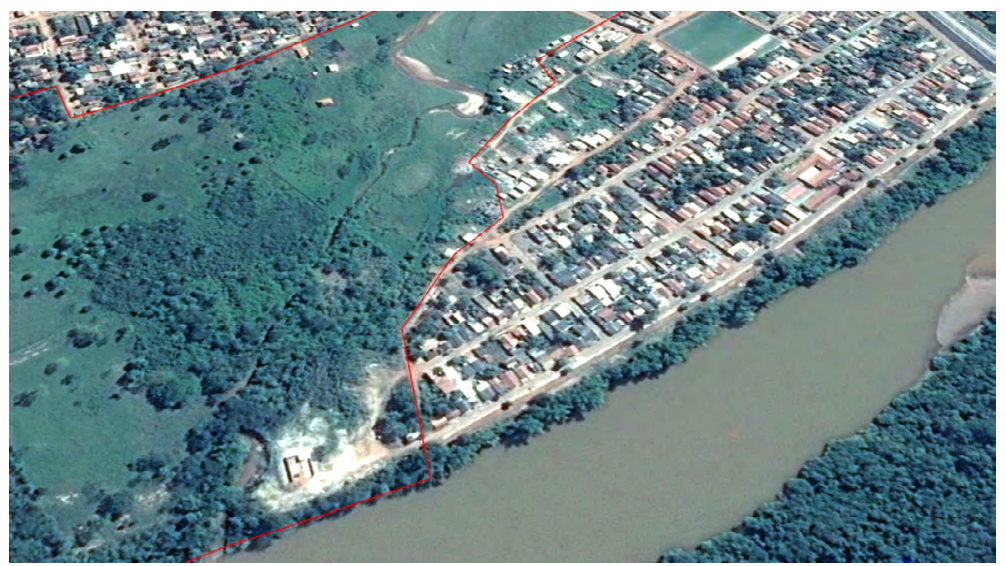

Figura 9. Cenário 6 com resquícios de vegetação e APPs do córrego e do Rio Vermelho desmatada

Fonte: Imagem de satélite disponível no Google Earth (06/02/2017)

O Cenário 7 possui cerca de 10,88 hectares, situado entre o Jardim Reis e o Jardim Sumaré, contemplando a APP do córrego Lageadinho. Nessa região da cidade, a urbanização invadiu muitos pontos da APP do córrego Lageadinho, fator que agravou e muito a poluição deste córrego. Por conta do adensamento demográfico, um Parque Urbano com essa proporção territorial se tornará um ponto de encontro para as práticas sociais dos moradores da Vila Operária e circunvizinhança. O local possui uma área desmatada que pode ser utilizada para instalar equipamentos urbanos, e um pequeno fragmento vegetacional próximo a APP do córrego, que está apto a criação de um Bosque (Figura 10). 


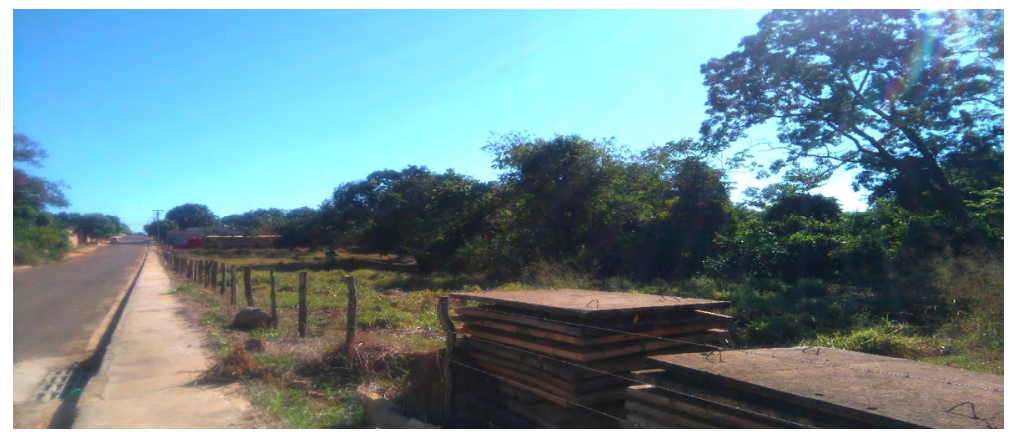

Figura10. Área vegetada próxima ao córrego Lageadinho no Cenário 7 Fonte: Raasch (2017).

Considerando que a Prefeitura pretende criar um Parque Urbano no bairro Alfredo de Castro, delimitamos a provável área apta a instalação de um Parque Urbano no bairro.

O Cenário 8 possui cerca de 31,69 hectares, contemplando um pequeno fragmento vegetacional que protege uma nascente, conforme informou o Secretário do Meio Ambiente, e ainda uma área relevante para construção de equipamentos no âmbito esportivo, cultual e de recreação, pois o respectivo bairro não dispõe de nenhuma infraestrutura básica (Figura 11).

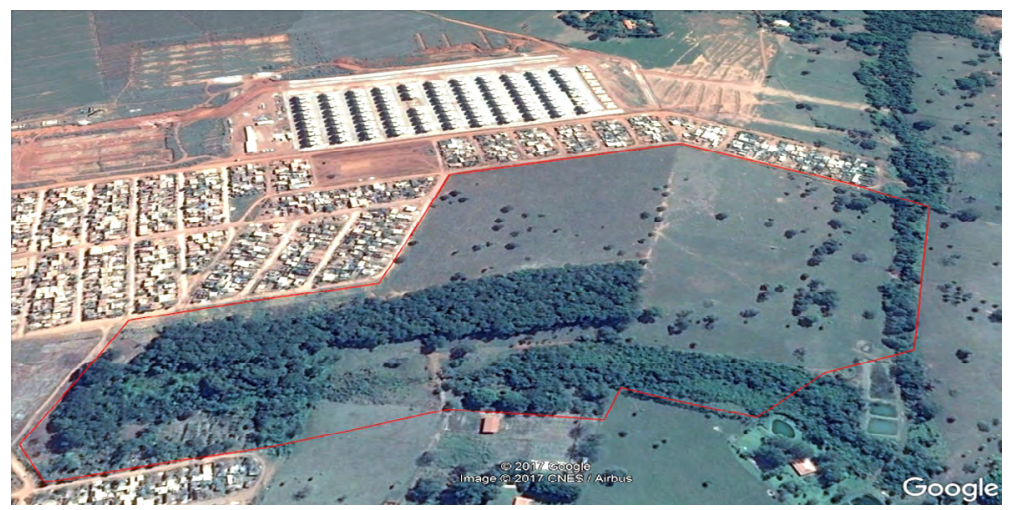

Figura 11. Fragmento vegetacional no Cenário 8

Fonte: Imagem de satélite disponível no Google Earth (06/02/2017).

O Alfredo de Castro está no extremo leste da mancha urbana, bem distante da área central, desta forma a implantação de um Parque Urbano resolveria parcialmente a melhoria das condições sociais e de vida dos moradores. 


\section{CONSIDERAÇÕES FINAIS}

Os cenários aptos mencionados localizam-se em zonas diferentes da cidade, de modo que a instalação de Parques Urbanos nos locais contribuirá para a democratização do acesso ao lazer e a promoção de qualidade de vida em Rondonópolis. Mas, antes de buscar recursos, é imprescindível cumprir as diretrizes do SNUC, realizando estudos ambientais previamente e desocupar as áreas, sobretudo as APPs dos córregos e do Rio vermelho, fazendo-se cumprir as leis ambientais, para que seja conservado e preservado os elementos biogeográficos existentes.

No entanto, a criação de Parques Urbanos é apenas uma das etapas, pois a elaboração de diretrizes de ação, gerenciamento e zoneamento ambiental, garantirá a sua manutenção e funcionalidade como um espaço de lazer, de pesquisa científica, Educação Ambiental, manifestações sociais e culturais, contribuindo assim, para elevação da qualidade de vida da população.

\section{REFERÊNCIAS}

ANDRADE, Inês El-Jaik. Jardins Históricos Cariocas: significação cultural e preservação. 2004.181 f. Dissertação em Mestrado em Arquitetura. UFRJ/FAU, Rio de Janeiro, 2004.

BARGOS, Danúbia Caporusso; MATIAS, Lindon Fonseca. Áreas Verdes Urbanas: Um Estudo De Revisão E Proposta Conceitual. REVSBAU, Piracicaba - SP, v.6, n.3, p.172-188, 2011. Disponível em: <http://www.revsbau.esalq.usp.br/artigos cientificos/artigo169-publicacao.pdf>. Acessado em: 10 de ago. de 2017.

BENINE, Sandra Medina; MARTIN, Encarnita Salas. Decifrando as Áreas Verdes Públicas. Revista Formação, n.17, volume 2 - p. 63-80, 2014. Disponível em: <http://revista.fct.unesp.br/index.php/formacao/article/viewFile/455/489http:// www.labs.ufpr.br/site/wp> Acessado em: 10 de ago. de 2017.

BRASIL. Conselho Nacional do Meio Ambiente. Resolução n. 369 de 28 de março de 2006.Disponívelem:\&lt;http://www.mma.gov.br/port/conama/legiabre. cfm?codlegi=489\&gt; Acessado em: 10 de Jan. 2016.

BRASIL. Lei n ${ }^{\circ}$ 9.985, de 18 de julho de 2000. Presidência da República da Casa Civil subchefia para assuntos jurídicos, Brasília, 18 de Jul. 2000. Disponível em: <http:// www.planalto.gov.br/CCivil 03/LEIS/L9985.htm>Acessado em: 05 de jan. 2015.

FERREIRA, ADJALME DIAS. Efeitos positivos gerados pelos Parques Urbanos: o caso do passeio público da cidade do Rio de Janeiro. 2005. 99 f. Dissertação (Mestrado em Ciência Ambiental) - Universidade Federal Fluminense, Rio de Janeiro, 2005. 
INSTITUTO BRASILEIRO DE GEOGRAFIA E ESTATìSTICA. População. Disponível em: <https://cidades.ibge.gov.br/v4/brasil/mt/rondonopolis/panorama> Acessado em: 17 de jun de 2017.

LIMA, Ana Maria Liner Pereira et al. Problemas de Utilização na Conceituação de Termos como Espaçoes Livres, Áreas Verdes e Correlatos. Anais do II Congresso Brasileiro de Arborização Urbana. São Luís/MA, 18 a 24 de setembro de 1994, pp. 539-553. Disponível em: <http://www.labs.ufpr.br/site/wp-content/ uploads/2014/07/lima anaisdecongressos cbau 1994.pdf> Acessado em: 10 de ago. de 2017.

LOBODA, Carlos Roberto; Angelis, Bruno Luiz Domingos. Áreas Verdes Públicas Urbanas: Conceitos, Usos E Funções. Revista do Centro de Ciências Agrárias e Ambientais, V. 1. No. 1 Jan/Jun, 2005. Disponível em: <file://C:/Users/NEIA/ Downloads/157-626-1-PB.pdf>. Acessado em: 10 de ago. de 2017.

MACEDO, Silvio Soares. Quadro do Paisagismo no Brasil. São Paulo: Coleção Quapá, 1999.

MACEDO, S. S.; SAKATA, F. G. Parque Urbanos no Brasil: Brazilian Urban Parks. São Paulo: Edusp, 2002.

MINISTÉRIO DO MEIO AMBIENTE. Parques e Áreas Verdes. Brasília, 2006. Disponível em: \&lt;http://www.mma.gov.br/port/conama/legiabre.cfm?codlegi=489\&gt; Acesso em: 10 de jan. 2016.

NEGRI, S. M. O processo de segregação sócio-espacial no contexto do desenvolvimento econômico da cidade de Rondonópolis - MT. 2005.195 f. Tese (doutorado em Geografia) - Instituto de Geociências e Ciências Exatas, Universidade Estadual Paulista, Rio Claro, 2008.

REZENDE, P. S. Qualidade Ambiental em Parques Urbanos: levantamento e análises de aspectos positivos e negativos do Parque Municipal Victório Siquierolli - Uberlândia/MG. Disponível em: <\&lt; http://www.observatorium.ig.ufu.br/ pdfs/3edicao/n10/04.pdf\&gt;> Acessado em: 15 de fev. de 2017.

RONDONÓPOLIS. Lei complementar no 043, de 28 de dezembro de 2006. Gabinete do Governo Municipal, Rondonópolis, 28 de Dez. 2006. Disponível em: <http://www.rondonopolis.mt.gov.br/Plano-Diretor.pdf > Acessado em: 30 de Julho de 2015.

SANTUCCI, J. As Promenades do Rio de Janeiro: O papel do Passeio Público, Praça Paris e Parque do Flamengo na história da paisagem carioca. 2003. $170 \mathrm{f}$. Dissertação (Mestrado em Ciências em Arquitetura) - Faculdade de Arquitetura e Urbanismo, Universidade Federal do Rio de Janeiro, Rio de Janeiro, 2003. 